\title{
Efficient and Cost-Effective Single Nucleotide Polymorphism Detection with Different Fluorescent Applications
}

BioTechniques 31:920-928(October 2001)

\author{
A. Aydin, H. Baron, \\ S. Bähring, H. Schuster, and \\ F.C. Luft \\ Humboldt University of Berlin, \\ Berlin, Germany
}

\begin{abstract}
Three methods-5' nuclease assay with TaqMan ${ }^{\circledR}$, minisequencing, and oligonucleotide ligation assay (OLA)—were com pared to detect five single nucleotide polymorphisms (SNPs) in three separate genes. Each method had advantages and disadvantages. The $5^{\prime}$ nuclease assay was the fastest and required only a single step. OLA was the most time consuming to optimize, but once running it was the least expensive method. Minisequencing was universal; however, the technique was also the most expensive. All three methods were reliable and highly effective. Investigators must consider their goals in terms of time, sample number, and expense when selecting among these genotyping techniques.
\end{abstract}

\section{INTRODUCTION}

With the sequencing of the entire human genome, single nucleotide polymorphisms (SNPs) will gain in significance. An industrial consortium is committed to identifying more than 300000 SNPs in the human genome (11). Gene mapping with SNP analysis has been shown to be feasible (9), and multiple SNP analyses in single genes or gene series are becoming commonplace. To master such complex genotyping needs, new technologies such as MALDI-TOF mass spectrometry, biochips, novel enzymes, and fluorophores are being developed $(6,12)$. However, investigators are currently faced with conventional technologies. We com pared three PCR-based methods for SNP classification, namely allelic discrimination using fluorescent probes with the TaqMan ${ }^{\circledR}$ system ( $5^{\prime}$ nuclease reaction), minisequencing with specific primers, fluorescence-marked ddNTPs, and a capillary sequencer, and an oligonucleotide ligation assay (OLA) relying on a conventional gel sequencer. Five different SNPs in three genes were studied. We studied an already known SNP in the $\alpha$-adducin gene. The $\alpha$-adducin gene has been implicated in the development of salt-sensitive hypertension (4). We selected two SNPs in the peroxisome proliferator activated receptor gamma (PPAR $\gamma$ ) gene. PPAR $\gamma$ may be related to dizygotic twinning and influences insulin-related effects, lipid metabolism, and body mass index; all are important to the growth process (3). We identified two SNPs in the retinoic acid receptor gamma (RXR $\gamma$ ) gene. RXR $\gamma$ binds DNA with other nuclear receptors and regulates gene expression; the PPAR $\gamma$ gene is an example (14). Advantages and disadvantages were encountered with each of the methods, and no single method was ideal for all applications.

\section{MATERIAL AND METHODS}

The DNA was prepared from the blood samples using the Genomix kit ${ }^{\circledR}$ (Talent, Triesta, Italy). For the 5' nuclease reaction with the TaqMan system $(5,8)$, the oligonucleotide sequences are given in Table 1. Fluorescent probes consisted of an oligonucleotide labeled with both a fluorescent reporter dye and a quencher dye. Both probes have the quencher dye TAMRA; however, each has its own specific reporter dye. One reporter oligonucleotide probe, labeled with TET, hybridizes with the wild-type allele. The other probe, labeled with FAM, hybridizes with the mutant allele. The reactions were carried out in a $12.5-\mu \mathrm{L}$ reaction volume, with $6.25 \mu \mathrm{L}$ Universal PCR Mastermix ${ }^{\circledR}$ (Applied Biosystems, Foster City, CA, USA), $50 \mathrm{nM}$ forward primer for the $\alpha$-adducin (C1380A) locus and $300 \mathrm{nM}$ for all the other loci, $300 \mathrm{nM}$ reverse primer for the $\alpha$-adducin $(\mathrm{C} 1380 \mathrm{~A})$ and $900 \mathrm{nM}$ for all the other loci, $100 \mathrm{nM}$ mutant allele probe and 
$200 \mathrm{nM}$ wild-type allele probe for the RXR $\gamma$ (T1050C) loci and $200 \mathrm{nM}$ both probes for the other loci, and $50 \mathrm{ng}$ genomic DNA. The PCR was conducted at $50^{\circ} \mathrm{C}$ for $2 \mathrm{~min}, 95^{\circ} \mathrm{C}$ for $10 \mathrm{~min}$, then 50 cycles at $95^{\circ} \mathrm{C}$ for $15 \mathrm{~s}$ and $60^{\circ} \mathrm{C}$ for $1 \mathrm{~min}$ for the loci $\alpha$-adducin (C1380A), PPAR $\gamma$ (C34G) and RXR $\gamma$ $(\mathrm{G}-381 \mathrm{~T}), 62^{\circ} \mathrm{C}$ for $1 \mathrm{~min}$ for the loci $\operatorname{PPAR} \gamma(\mathrm{C} 1431 \mathrm{~T})$ and RXR $\gamma(\mathrm{T} 1050 \mathrm{C})$. The initial $50^{\circ} \mathrm{C}$ for $2 \mathrm{~min}$ and the presence of the enzyme Amp Erase ${ }^{\circledR}$ (Applied Biosystems) are required to prevent the re-amplification of any carryover PCR products. The PCR am plifications were performed in a model 9600 thermal cycler (Applied Biosystems). The samples were analyzed using the TaqMan 7700 reader (Applied Biosystems). We used the Sequence Detection System software V. 1.63 for analyzing the samples.

For the minisequencing reaction (13), the different loci for all five SNPs were amplified with primer shown in Table 1. The total PCR volume was 15 $\mu \mathrm{L}$. The PCR mixture contained 10 $\mathrm{mM}$ Tris- $\mathrm{HCl}$ (pH 8.3), $50 \mathrm{mM} \mathrm{KCl}$, $2.5 \mathrm{mM} \mathrm{MgCl} \mathrm{M}_{2}, 250 \mathrm{mM}$ each dNTP (dATP, dCTP, dGTP, and dTTP; Amersham Pharmacia Biotech, Piscataway, NJ, USA), $50 \mathrm{ng}$ genomic DNA, and 0.6 U AmpliTaq Gold ${ }^{\circledR}$ DNA Polymerase (Applied Biosystems). After PCR amplification, we used CentriSep $^{\mathrm{TM}}$ spin columns (Princeton Separations, Adelphia, NJ, USA) or $1 \mathrm{U}$ alkaline phosphatase/1 U exonuclease I (Amersham Pharmacia Biotech) to degenerate the PCR primers and dephosphorolyte dNTPs. The sequences for the minisequencing primer are shown in Table 1 . The reaction conditions were a $10-\mu \mathrm{L}$ reaction volume, $2.5 \mu \mathrm{L}$ ready reaction premix [containing $(\mathrm{F})$ ddNTP, Taq DNA polymerase, buffer; ABI $\quad$ PRISM $^{\circledR} \quad$ SNaPshot $^{\mathrm{TM}}$ ddNTP Primer Extension Kit; Applied Biosys- tems), $10 \mathrm{nM}$ minisequencing primer and 0.15 pmol purified PCR product as template. The minisequencing conditions were as follows: 25 cycles consisting of a heat denaturation step of 10 $\mathrm{s}$ at $96^{\circ} \mathrm{C}$, an annealing step of $10 \mathrm{~s}$ at $50^{\circ} \mathrm{C}$, and an extension step of $30 \mathrm{~s}$ at $60^{\circ} \mathrm{C}$. To remove the $5^{\prime}$ phosphoryl groups from the unincorporated fluorescence-marked ddNTP, we added $2 \mathrm{U}$ shrimp alkaline phosphatase (Roche Molecular Biochemicals, Indianapolis, IN, USA) to the minisequencing reaction and incubated at $37^{\circ} \mathrm{C}$ for $1 \mathrm{~h}$. The separation was done on the ABI PRISM 310 with POP4 polymer green capillary and with GS STR POP4 E module. The signals were analyzed using Collection software V. 1.2 and the GeneScan ${ }^{\circledR}$ Analysis software V 3.1.

For the OLA $(1,2)$, the different loci for all five SNPs were amplified with primers described in the minisequencing reaction. Three to $5 \mu \mathrm{L}$ (50 ng PCR

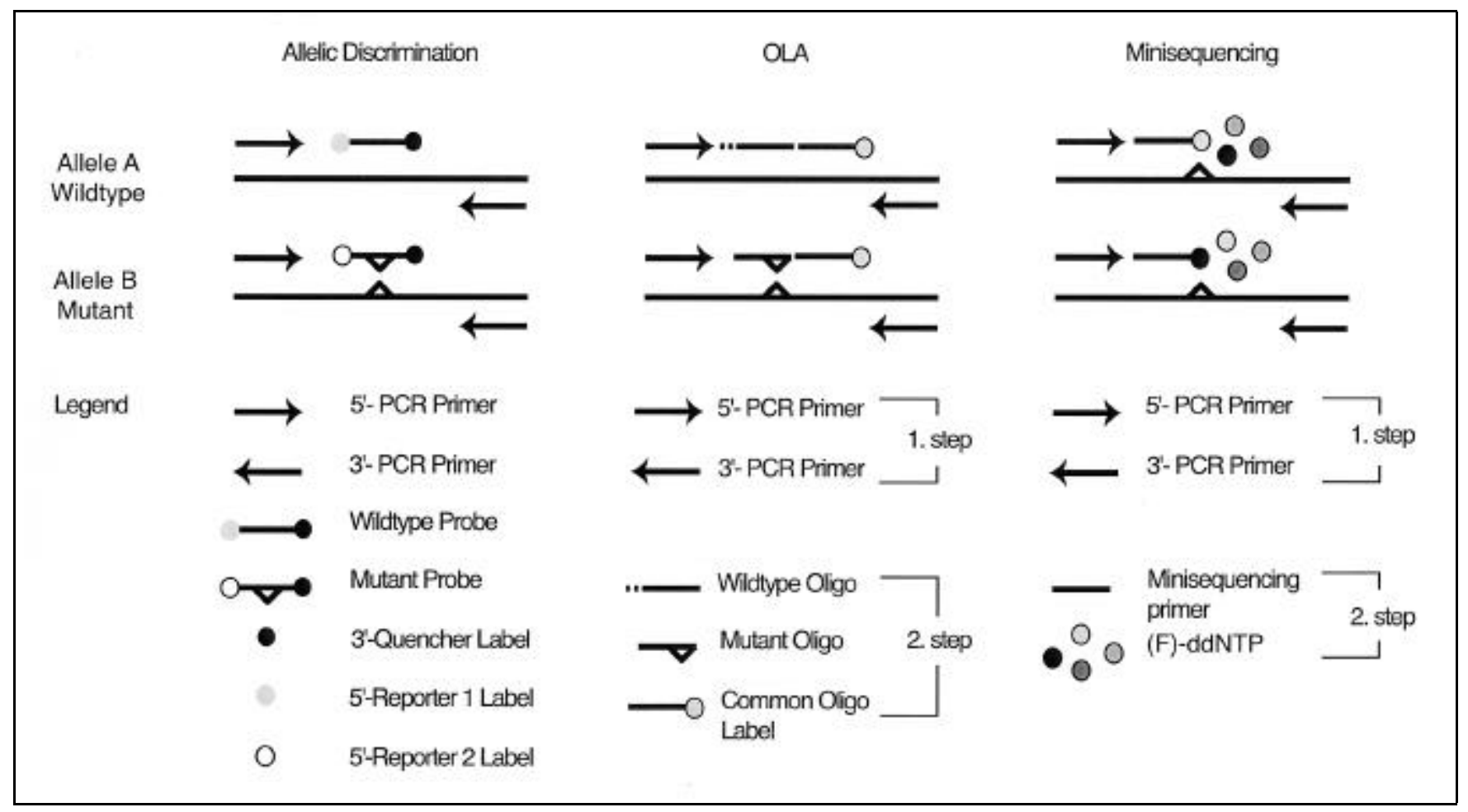

Figure 1. The 5' nuclease assay, OLA, and minisequencing reaction. In the 5' nuclease assay (allelic discrimination), probes are used to classify the mutation. Together with the two PCR primers flanking a polymorphism, two additional allele-specific probes are used spanning the SNP. Both probes are marked with a quencher fluorescence molecule (TAMRA) at the $3^{\prime}$ end. A different reporter fluorescence molecule (TET or FAM) resides at the $5^{\prime}$ end. During the PCR, the probes hybridize and are completely degraded by the $5^{\prime}$ nuclease activity of Taq DNA polymerase. For the OLA, a PCR product containing the SNP is used. To distinguish the sequence variations, we used two allele-specific oligonucleotides of different length (wild-type oligonucleotide and mutant oligonucleotide). A third oligonucleotide is labeled (common oligonucleotide). At the $5^{\prime}$ end of the common oligonucleotide, one of the allele-specific oligonucleotides is ligated by the thermostable DNA ligase. For the minisequencing reaction, a PCR product distinguishes the sequence variations. A detection primer anneals to the nucleic acid sequence at the $3^{\prime}$ end of the nucleotide position of the mutation. ddNTPs labeled with four different fluorescent dyes serve for the detection of the product and terminate the reaction. 


\section{Research Report}

Table 1. Sequences of Oligonucleotides for Three Different SNP Applications

\begin{tabular}{|c|c|c|}
\hline $\begin{array}{l}\text { Locus Name/ } \\
\text { Polymorphism }\end{array}$ & $\begin{array}{c}\text { Application } \\
\text { Oligonucleotide Name }\end{array}$ & Oligonucleotide Sequence $\left(5^{\prime} \rightarrow 3^{\prime}\right)$ \\
\hline$\alpha$-adducin & F-primera & TCGTCCACACCTTAGTCTTCGA \\
\hline \multirow[t]{7}{*}{$(\mathrm{C} 1380 \mathrm{~A})$} & R-primerb & GCAGCGGGAGAAGACAAGAT \\
\hline & wt probec & TET-TCCATTCTGCCCTTCCTCGGAAG-TAMRA \\
\hline & $\mathrm{mt}$ probed & FAM-TTCCATTCTGCCATTCCTCGGAAG-TAMRA \\
\hline & OLA coe & PTTCCTCGGAAGCT-TAMRA \\
\hline & OLA muf & AАATTCCATTCTGCCA \\
\hline & OLA wtg & TTCCATTCTGCCC \\
\hline & Mini sh & GACTGCTTCCATTCTGCC \\
\hline PPARy & F-primera & TGTTATGGGTGAAACTCTGGGA \\
\hline \multirow{9}{*}{$(\mathrm{C} 34 \mathrm{G})$} & R-primerb & GGAACTTTACCTTGTGATATGTTTGC \\
\hline & $\mathrm{F}^{\prime}$-primera' & TGTTATGGGTGAAACTCTGG \\
\hline & $\mathrm{R}^{\prime}$-primer $\mathrm{b}^{\prime}$ & CACAACCTGGAAGACAAACT \\
\hline & wt probec & TET-TCTCCTATTGACCCAGAAAGCGATTCC-TAMRA \\
\hline & mt probed & FAM-TCTCCTATTGACGCAGAAAGCGATTCC-TAMRA \\
\hline & OLA $\operatorname{co}^{e}$ & PCAGAAAGCGATTCCT-TAMRA \\
\hline & OLA muf & AAAAAAAGATTCTCCTATTGACG \\
\hline & OLA wtg & AAAAAGATTCTCCTATTGACC \\
\hline & Mini sh & AGTGAAGGAATCGCTTTCTG \\
\hline \multirow{10}{*}{$\begin{array}{l}\text { PPARy } \\
(\mathrm{C} 1431 \mathrm{~T})\end{array}$} & F-primera & GCCAAGCTGCTCCAGAAAAT \\
\hline & R-primerb & GAGCGGGTGAAGACTCATGTC \\
\hline & $\mathrm{F}^{\prime}$-primera' & CCCAGGTTTGCTGAATGTGAA \\
\hline & $\mathrm{R}^{\prime}$-primer $\mathrm{b}^{\prime}$ & TGGCAGTGGCTCAGGACTCT \\
\hline & wt probec & TET-TGTCACGGAACACGTGCAGCTACTG-TAMRA \\
\hline & $\mathrm{mt}$ probed & FAM-TTGTCACGGAACATGTGCAGCTACTG-TAMRA \\
\hline & OLA coe & pGTGCAGCTACTGCAG-TAMRA \\
\hline & OLA muf & AAAAAAATTGTCACGGAACAT \\
\hline & OLA wtg & AAAAATTGTCACGGAACAC \\
\hline & Mini $s^{h}$ & AGACAGATTGTCACGGAACA \\
\hline \multirow{10}{*}{$\begin{array}{l}\text { RXRY } \\
\text { (G-381T) }\end{array}$} & F-primera & GATAATAGATCGTGCCACCCG \\
\hline & R-primerb & TTAACTCAGGGTTGGGCTGC \\
\hline & $\mathrm{F}^{\prime}$-primera $\mathrm{a}^{\prime}$ & TTTCACAGATCAAATACCAAGTA \\
\hline & $\mathrm{R}^{\prime}$-primer $\mathrm{b}^{\prime}$ & GAAGTGAGAATAATTTCCATACAT \\
\hline & wt probec & TET-GACGCGCCGGGAGCTGGA-TAMRA \\
\hline & mt probed & FAM-GGACGCGCCTGGAGCTGGA-TAMRA \\
\hline & OLA coe & pGGCGCGTCCC-FAM \\
\hline & OLA muf & AAAAAAAAAAAAAAAACTCTTCCAGCTCCA \\
\hline & OLA wtg & AAAAAAAAAAAACTCTTCCAGCTCCC \\
\hline & Mini sh & GCGACTCTTCCAGCTCC \\
\hline \multirow{10}{*}{$\begin{array}{l}\text { RXRY } \\
(\mathrm{T} 1050 \mathrm{C})\end{array}$} & F-primera & CCTGTTACTTACGGTTTTCTCATTACC \\
\hline & R-primerb & TTGTCCATCTGCATGTCTTTCATT \\
\hline & $F^{\prime}-$ primera' & GGAAACAGAGTGGGCTTATAA \\
\hline & $\mathrm{R}^{\prime}$-primerb' & CAACAACATGGGAGCACTG \\
\hline & wt probec & TET-TGTTTCCTGTTAACAGAGTTCTAACTGAGCTGGT-TAMRA \\
\hline & mt probed & FAM-TGTTTCCTGTTAACAGAGTCCTAACTGAGCTGGT- TAMRA \\
\hline & OLA coe & pCTAACTGAGCTGGTTT-FAM \\
\hline & OLA mu & AAAAAATTCCTGTTAACAGAGTC \\
\hline & OLA wtg & AAATTCCTGTTAACAGAGTT \\
\hline & Mini $s^{h}$ & TTGGAAACCAGCTCAGTTAG \\
\hline
\end{tabular}




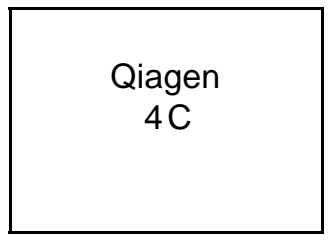

Circle Reader Service No. 232 


\section{Research Report}

Table 1 Continued

aPCR forward primer for $5^{\prime}$ nuclease assay

bPCR reverse primer for $5^{\prime}$ nuclease assay

a'PCR forward primer for OLA and minisequencing

b'PCR reverse primer for OLA and minisequencing

c5' nuclease assay wild-type probe

d5' nuclease assay mutant probe

e OLA common oligonucleotide

fOLA mutant oligonucleotide

gOLA wild-type oligonucleotide

$\mathrm{h}_{\text {minisequencing oligonucleotide }}$ product, depending on the PCR performance) of the PCR product were used for the ligase reaction. All OLA reactions were carried out in $20 \mu \mathrm{L}$ reaction volume containing $20 \mathrm{mM}$ Tris- $\mathrm{HCl}$, $\mathrm{pH} 7.6,25 \mathrm{mM}$ potassium acetate, 10 $\mathrm{mM}$ magnesium acetate, $10 \mathrm{mM}$ DTT, 1 mM NAD, 0,1\% Triton ${ }^{\circledR} \mathrm{X}-100,2 \mathrm{U}$ thermostable Taq DNA ligase (New England Biolabs, Beverly, MA, USA). The concentrations for each common, wild-type, and mutant oligonucleotide were as follows: $\alpha$-adducin $(\mathrm{C} 1380 \mathrm{~A})$, 50, 50, and $50 \mathrm{nM}$; PPAR $\gamma(\mathrm{C} 34 \mathrm{G}), 30$, 30, and $30 \mathrm{nM}$; RXR $\gamma(\mathrm{G}-381 \mathrm{~T}), 60$, 120, and $120 \mathrm{nM}$; PPAR $\gamma(\mathrm{C} 1431 \mathrm{~T})$, 60, 60, and $60 \mathrm{nM}$; RXR $\gamma$ (T1050C), 20, 20, and $20 \mathrm{nM}$. All OLA oligonucleotide sequences are given in Table 1 .

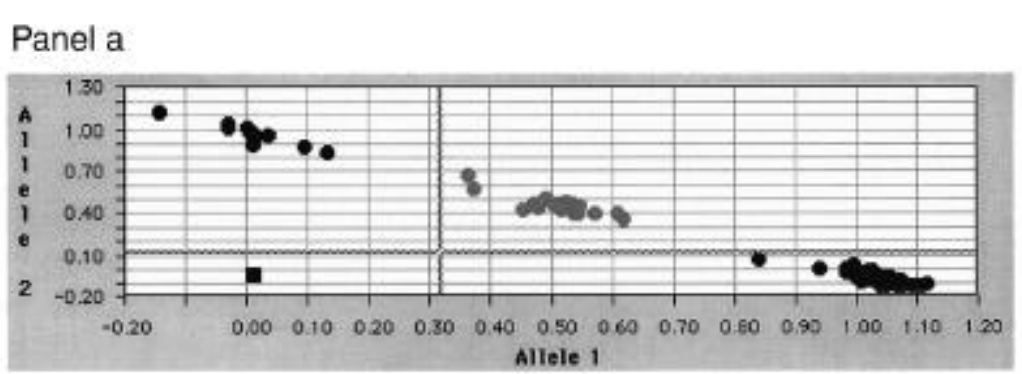

Panel b

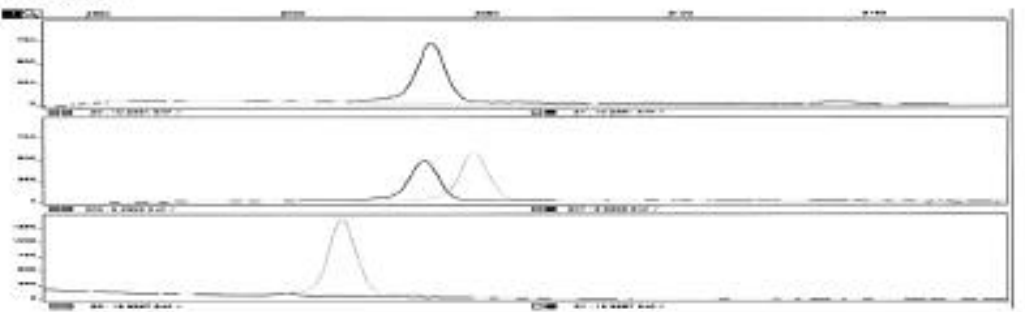

Panel c

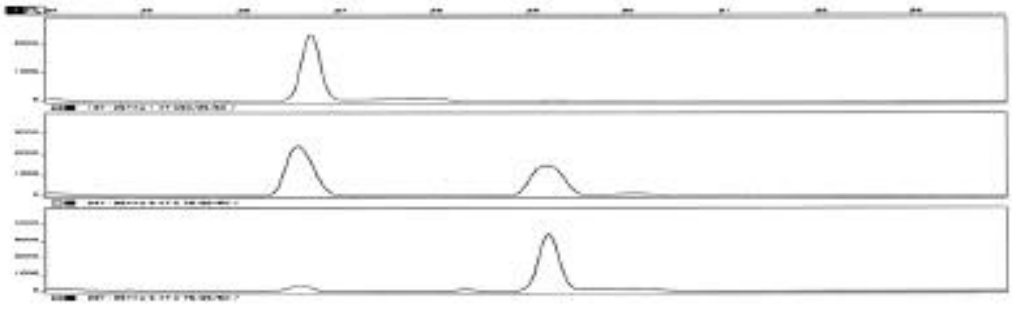

Figure 2. The $\alpha$-adducin C1380A SNP. (a) Allele 1 signal versus allele 2 signal for the samples run in the allelic discrimination. Black squares are the eight negative controls. Homozygous persons for allele 2 (left), heterozygous persons (middle), and homozygous persons for allele 1 (right). (b) Minisequencing reaction results. (c) OLA results. Upper is wild-type, middle is heterozygous, and lower is homozygous mutant allele. 


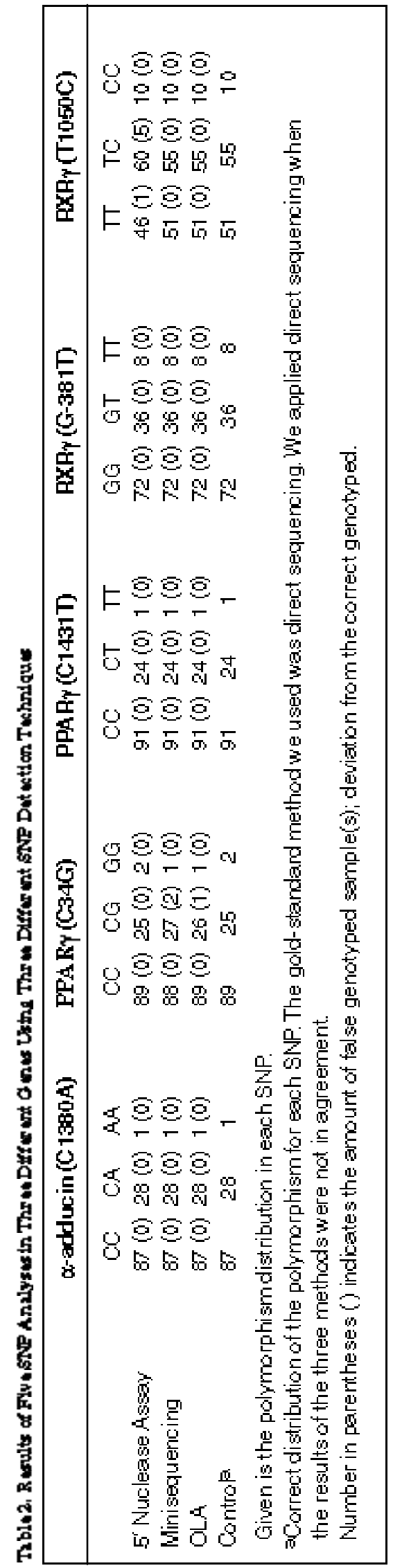

Table 3. Comparison of Three Different Methods for SNP Detection

\begin{tabular}{|c|c|c|c|}
\hline \multicolumn{3}{|c|}{ 5'Nuclease } & OLA \\
\hline $\begin{array}{l}\text { Costs/reaction } \\
\qquad(U S \$)^{a}\end{array}$ & about 1.5 & about 2 & about 1 \\
\hline $\begin{array}{l}\text { Detection } \\
\text { instrument }\end{array}$ & 7700 & $310 / 377^{c}$ & $310 / 377^{c}$ \\
\hline Sensitivity & 50 ng genomic DNA & 30 ng PCR product & 50 ng PCR product \\
\hline Run time ${ }^{b}$ & $10 \mathrm{~s}$ & $30 \mathrm{~h} / 2 \mathrm{~h}$ & $30 h / 2 h$ \\
\hline \multicolumn{4}{|c|}{$\begin{array}{l}\text { alncluding all consumable materials, probes, and oligonucleotides for } \\
2500 \text { reactions; btime required for running } 96 \text { samples; cusing } 377 \text { sequencer with } \\
96 \text { lanes. }\end{array}$} \\
\hline
\end{tabular}

Linear product amplification was achieved by 20 cycles of $94^{\circ} \mathrm{C}$ for $30 \mathrm{~s}$ and $45^{\circ} \mathrm{C}$ for $3 \mathrm{~min}$, followed by heating at $99^{\circ} \mathrm{C}$ for $10 \mathrm{~min}$ in a model 9600 thermal cycler (Applied Biosystems) to inactivate the ligase. A $2-\mu \mathrm{L}$ aliquot of each OLA product was mixed with 2.5 $\mu \mathrm{L}$ deionized formamide, $0.5 \mu \mathrm{L}$ dextran blue loading buffer, and $0.5 \mu \mathrm{L}$ GeneScan-500 ROX size marker. The mixture was denatured at $95^{\circ} \mathrm{C}$ for 3 min and then rapidly cooled on ice before loading the gel. OLA products were electrophoresed for $2 \mathrm{~h}$ at $3000 \mathrm{~V}$ on an ABI 377 fluorescence-scanning DNA sequencer with an $8 \%$ acrylamide:bisacrylamide (19:1) denaturing gel containing $8.3 \mathrm{M}$ urea, $89 \mathrm{mM}$ Tris, $89 \mathrm{mM}$ boric acid, and $2 \mathrm{mM}$ EDTA.

The gel thickness was $0.4 \mathrm{~mm}$, and the well-to-read length was $24 \mathrm{~cm}$. The resulting gels were analyzed for peak color and fragment size by using the collection software V. 3.1, GeneScan ${ }^{\circledR}$ Analysis software V. 3.02, and Genotyper $^{\circledR}$ software V. 2.0.

\section{RESULTS AND DISCUSSION}

We compared three easy methods for SNP determination in 116 samples. All 116 samples were scanned for five biallelic polymorphisms in three separate genes with the applications described above. Altogether, 1740 genotypes were produced. All three methods were based on PCR. Therefore, the quality of the three assays was dependent on primer hybridization, amplification, and, in the case of OLA, ligation. Generally, primer software tools must be used. We re- lied on Primer Express ${ }^{\mathrm{TM}}$ (Version 1 for Macintosh ${ }^{\circledR}$, Power PC ${ }^{\circledR}$; Applied Biosystems) and Oligo ${ }^{\circledR}$ (Version 4.06 for Macintosh; National Bioscience) to verify the primer dimer form and other structures, such as hairpins. All three methods showed high sensitivity and specificity. Therefore, all three are attractive for SNP detection.

The principles behind the three assays are shown in Figure 1. In the allelic discrimination experiment, the 96 samples, including eight human DNA homozygous controls for allele 1, eight human DNA homozygous controls for allele 2, and eight negative controls were analyzed. The TaqMan instrument reads and records each individual sam ple and determines which alleles are present. An example is shown in Figure $2 \mathrm{a}$. The black square indicates the eight negative controls. Homozygous allele 1 , homozygous allele 2 , and heterozygous individuals were clearly separated. The inclusion of eight controls for allele 1 and eight controls for allele 2 provided a precision of $99.7 \%$ for the analysis. A control DNA sample is a prerequisite for this assay. For a successful allelic discrimination, two optimization steps were executed. We pipetted a primer matrix and a probe matrix. For the primer matrix, we used concentrations of 50, 300, and $900 \mathrm{nM}$ for each primer. For the probe matrix, we used concentrations of 50, 100, and $200 \mathrm{nM}$ for each probe. To analyze the best yield for the PCR product, we used the "real-time" option. The TaqMan assay was performed in $12.5 \mu \mathrm{L}$ volume, instead of $50 \mu \mathrm{L}$ as suggested by the manufacturer. Reducing the volume in- 
dicates no loss of genotypes quantities or qualities (data not shown). Small volumes can be cycled more efficiently in the thermal cycler machine, which reduces the costs. To produce the maximum of signal strength, an addition of PCR cycles to 50 should be done. We suggest the allelic discrimination assay for high-throughput projects requiring more than 250 genotypes a day. The $5^{\prime}$ nuclease assay incorporates ease of design and the commercial availability of analysis software, which provides rapid data analysis. The reaction run is sim ple and fast. Contrary to OLA, the allelic discrimination offers no high multiplex ability (7). However, by the use of modified oligonucleotides and different dyes such as FAM, TET, VIC, and NED, a higher multiplex ability could be achieved. However, the software for this option is not yet available.

Contrary to allelic discrimination, the minisequencing reaction requires more steps. First, together with two PCR primers that flank a polymorphism, a PCR must be performed. After the PCR amplification, the PCR product is in solution along with primers (oligonucleotides), dNTPs, enzyme, and buffer components. To avoid participation in the subsequent minisequencing reaction, PCR primers and unincorporated dNTPs must be removed. This problem represents a bottleneck because more work steps are needed in the minisequencing technique. We used either Centri-Sep columns or a mixture of alkaline phosphatase and $E$. coli exonuclease I for purifying the PCR products. In our opinion, the Centri-Sep column preparation is not the best choice for purification of PCR products because it is too time consuming. Figure $2 \mathrm{~b}$ shows the results from three samples with the three possible genotypes analyzed by the minisequencing reaction. We used $2.5 \mu \mathrm{L}$ minisequencing reaction mixture instead of $5 \mu \mathrm{L}$ as suggested by the manufacturer. For the best sensitivity, we suggest $30 \mathrm{ng}$ PCR product as tem plate for the reaction. An advantage compared to allelic discrimination and to the oligonucleotide ligation assay is that all four variable nucleotides are identified at the same reaction. The minisequencing reaction is universal and does not require a fluorescent marked oligonucleotide. Therefore, the flexibility is high. The minisequencing reaction with varying length of primers is also suitable for analyzing more than one SNP at a time (13). The costs and the expenditure of the minisequencing reaction are somewhat higher than the 5 ' nuclease assay and the OLA. The reaction is also the most complex. We recommend the minisequencing reaction for a few samples in which the investigator would like to determine whether or not one or more polymorphisms are relevant for a particular study.

The OLA combines both the PCR and ligase reactions. The PCR product serves as template. An average quantity of $50 \mathrm{ng}$ PCR product results in the most optimal yield. For each polymorphism, we pipetted a matrix between 10 and $200 \mathrm{nM}$ (in 10-nM steps) with all three specific oligonucleotides. This complex step is essential to find the optimal conditions. In our study, all primer concentrations were situated between $20 \mathrm{nM}$ and $120 \mathrm{nM}$. Temperature modifications have almost no influence on the ligase reaction. The optimal temperature for the Taq DNA ligase used is $45^{\circ} \mathrm{C}$. Figure $2 \mathrm{c}$ shows the results from three sam ples analyzed by OLA. All three genotypes can be clearly distinguished from each other. The OLA is suitable when many samples must be run or when multiple SNPs must be detected simultaneously. OLA takes the most time for optimization; however, once running, it is the least expensive method.

In the OLA and minisequencing reactions, the products are separated and detected by the gel or capillary system. In the allelic analysis, the fluorescent signal for the allelic discrimination is measured directly in PCR tubes (10). For all SNP genotyping experiments, we included two controls that contained no template DNA. Both negative controls showed no signal in every reaction. A total of 580 genotypes gave almost identical results with all three methods. The distribution of the polymorphism for each SNP is given in Table 2.

The control method (gold standard) we employed to compare the three methods was direct sequencing of the SNPs. We applied direct sequencing when the results of the three methods were not in agreement. All three applications showed only a single error in a single SNP. OLA and minisequencing 
produced a single error in the PPAR $\gamma$ C34G SNP (1\% and 2\%, respectively). The $5^{\prime}$ nuclease assay produced a $5 \%$ error rate in the RXR $\gamma$ T1050C SNP. These errors are negligible because the most frequent reason for failure is lack of product amplification. Failure to am plify the product results from additional changes in the PCR conditions. Only in the case of RXR $\gamma$ (T1050C) polymorphism was the error high at 5\%; this was because the probe for this polymorphism was too long (>30 nucleotides). The probe was designed in a particularly A/T-rich region. As a consequence, the signal strength was decreased, which resulted in false allelic discrimination. Contrary to the two other applications, the probes were dependent on the base composition and probe melting temperature. The advantages and disadvantages, in our view, are given in Table 3. Costs (in US dollars) were estimated based on prices in Germany. Laboratory costs and salaries are not included.

Laboratory automation requirements for all three methods are similar. Pipet robots attain high precision, avoid random errors, and provide a homogeneous signaling pattern on a gel separation system, capillary separation system, or fluorescence emission system. Further cost reduction can be achieved by scaling the reaction volumes down and using a oneway pipetting system. The utility of the three methods is the genotyping of known mutations in large numbers of subjects. Hundreds of samples can be analyzed daily. All three applications can be done easily. The available software makes all three assays attractive and independent of interference. Finally, mutation detection by all three methods is not limited to SNP detection; all three are also generally applicable for detecting deletion mutations.

\section{REFERENCES}

1.Barany, F. 1991. Genetic disease detection and DNA amplification using cloned thermostable ligase. Proc. Natl. Acad. Sci. USA 88:189-193.

2.Baron, H., S. Fung, A. Aydin, S. Bahring, F.C. Luft, and H. Schuster. 1996. Oligonucleotide ligation assay (OLA) for the diagnosis of familial hypercholesterolemia. Nat. Biotechnol. 14:1279-1282.

3.Busjahn, A., H. Knoblauch, H.D. Faulhaber, A. Aydin, R. Uhlmann, J. Tuomile- hto, J. Kaprio, P. Jedrusik et al. 2000. A region on chromosome 3 is linked to dizygotic twinning. Nat. Genet. 26:398-399.

4.Cusi, D., C. Barlassina, T. Azzani, G. Casari, L. Citterio, M. Devoto, N. Glorioso, C. Lanzani et al. 1997. Polymorphisms of $\alpha$ adducin and salt sensitivity in patients with essential hypertension. Lancet 349:1353-1357.

5.Happich, D., R. Schwaab, P. Hanfland, and D. Hoernschemeyer. 1999. Allelic discrimination of factor $\mathrm{V}$ Leiden using a $5^{\prime}$ nuclease assay. Thromb. Haemost. 82:1294-1296.

6.Lipshutz, R.J., S.P. Fodor, T.R. Gingeras, and D.J. Lockhart. 1999. High density synthetic oligonucleotide arrays. Nat. Genet. $21: 20-24$.

7.Livak, K.J., S.J. Flood, J. Marmaro, W. Giusti, and K. Deetz. 1995. Oligonucleotides with fluorescent dyes at opposite ends provide a quenched probe system useful for detecting PCR product and nucleic acid hybridization. PCR Methods Appl. 4:357-362.

8.Livak, K.J., J. Marmaro, and J.A. Todd. 1995. Towards fully automated genome-wide polymorphism screening. Nat. Genet. 9:341342 .

9.Martin, E.R., J.R. Gilbert, E.H. Lai, J. Riley, A.R. Rogala, B.D. Slotterbeck, C.A. Sipe, J.M. Grubber et al. 2000. Analysis of association at single nucleotide polymorphisms in the APOE region. Genomics 63:712.

10.Morin, P.A., R. Saiz, and A. Monjazeb. 1999. High-throughput single nucleotide polymorphism genotyping by fluorescent $5^{\prime}$ exonuclease assay. BioTechniques 27:538544.

11.Roses, A.D. 2000. Pharmacogenetics and future drug development and delivery. Lancet 355:1358-1361.

12.Ross, P., L. Hall, I. Smirnov, and L. Haff. 1998. High level multiplex genotyping by MALDI-TOF mass spectrometry. Nat. Biotechnol. 16:1347-1351.

13.Syvanen, A.C. 1999. From gels to chips: "minisequencing" primer extension for analysis of point mutations and single nucleotide polymorphisms. Hum. Mutat. 13:1-10.

14.Zhao, Q., S.A. Chasse, S. Devarakonda, M.L. Sierk, B. Ahvazi, and F. Rastinejad. 2000. Structural basis of RXR-DNA interactions. J. Mol. Biol. 296:509-520.

Received 10 July 2000; accepted 7 May 2001.

Address correspondence to:

Atakan Aydin

Franz Volhard Clinic

Wiltberg Strasse 50

13122 Berlin, Germany

e-mail: aydin@fuk-berlin.de 